showed patent flow diverter(s) with or without stent(s). One patient had a 1 year follow up only which showed complete occlusion of the pseudoaneurysm with a patent flow diverter. No significant in-device stenosis was identified in any followup case.

Conclusion Use of flow diverters, in some cases in conjunction with (carotid) stents, is an effective treatment option for cervical carotid artery dissections, especially loop dissections with or without associated pseudo aneurysms.

Disclosures J. Singh: None. A. Kuhn: None. K. de Macedo Rodrigues: None. F. Massari: None. M. Gounis: 1; C; National Institutes of Health (NIH), the United States - Israel Binational Science Foundation, Anaconda, ApicBio, Axovant, Cerenovus, Cook Medical, Gentuity, Imperative Care, InNeuroCo, Magneto, Mic. 2; C; Cerenovus, Imperative Care, phenox, Medtronic Neurovascular, Route 92 Medical, Stryker Neurovascular. 4; C; Imperative Care, InNeuroCo and Neurogami. A. Puri: 1; C; NIH, Cerenovus, Stryker Neurovascular and Medtronic. 2; C; Stryker, Cerenovus, Medtronic, Microvention, QApel, Perfuze Medical, Arsenal Medical, Merit Medical. 4; C; InNeuroCo Inc, Galaxy therapeutics, Agile Medical, Perfuze medical and NTI.

\section{P-040 MAJOR COMPLICATIONS OF DURAL VENOUS SINUS STENTING FOR IDIOPATHIC INTRACRANIAL HYPERTENSION: CASE SERIES AND MANAGEMENT CONSIDERATIONS}

${ }^{1} \mathrm{R}$ Townsend*, ${ }^{2} \mathrm{~A}$ Jost, ${ }^{3} \mathrm{M}$ Amans, ${ }^{4} \mathrm{~F}$ Hui, ${ }^{5} \mathrm{M}$ Bender, ${ }^{6} \mathrm{~S}$ Satti, ${ }^{7} \mathrm{R}$ Maurer, ${ }^{8} \mathrm{~K}$ Liu, ${ }^{9} \mathrm{~W}$ Brinjikji, ${ }^{1} \mathrm{~K}$ Fargen. ${ }^{1}$ Neurosurgery, Wake Forest, Winston salem, NC; ${ }^{2}$ Wake Forest, Winston salem, NC; ${ }^{3}$ Neurosurgery, University of California-San Francisco, San Francisco, CA; ${ }^{4}$ Neurosurgery, Johns Hopkins Hospital, Baltimore, MD; ${ }^{5}$ University of Rochester Medical Center, Rochester, NY; ${ }^{6}$ Christiana Care Health System, Newark, DE; ${ }^{7}$ Penn State Health, Hershey, PA; ${ }^{8}$ University of Southern California, Los Angeles, CA; ${ }^{9}$ Mayo Clinic, Rochester, MN

\subsection{6/neurintsurg-2021-SNIS.76}

Introduction Venous sinus stenting (VSS) is a safe, effective, and increasingly popular treatment option for selected patients with idiopathic intracranial hypertension (IIH). Serious complications associated with VSS are rarely reported.

Methods Serious complications after VSS were identified retrospectively from multicenter databases. The cases are presented and management strategies are discussed.

Cases Six major acute and chronic complications after VSS were selected from a total of 811 VSS procedures and 1466 venograms for IIH. These included an acute subdural hematoma from venous extravasation, cases of both intraprocedural and delayed stent thrombosis, an ultimately fatal cerebellar hemorrhage resulting in acute obstructive hydrocephalus, venous microcatheter perforation during venography and manometry, and a patient who developed SAH and SDH after cerebellar cortical vein perforation. The 6 cases are reviewed and learning points regarding complication avoidance and management are presented.

Conclusion We report on 6 rare, major complications after VSS for IIH. Familiarity with these potential complications and appropriate timely management may allow for good clinical outcomes.

Disclosures R. Townsend: None. A. Jost: None. M. Amans: None. F. Hui: None. M. Bender: None. S. Satti: None. R. Maurer: None. K. Liu: None. W. Brinjikji: None. K. Fargen: None.

\section{P-041 CHRONIC HEADACHES AND MIDDLE MENINGEAL ARTERY EMBOLIZATION}

J Catapano*, K Karahalios, V Srinivasan, J Baranoski, C Rutledge, T Cole, A Ducruet, F Albuquerque, A Jadhav. Neurosurgery, BNI, Phoenix, AZ

\subsection{6/neurintsurg-2021-SNIS.77}

Background The middle meningeal artery (MMA) has been implicated in chronic headaches, but no studies have examined the relationship between MMA embolization and headaches.

Methods Patients treated with MMA embolization for a chronic subdural hematoma (cSDH) (1/1/2018-12/31/2020) were retrospectively assessed. Patients with a Glasgow Coma Scale (GCS) score of 15 on discharge received a follow-up phone call to assess their history of chronic headache, defined as a headache $\geq 2$ years before the $\mathrm{cSDH}$ and symptoms $\geq 2$ days/month. A Headache Impact Test (HIT-6) was performed during the follow-up phone call. The primary outcome was resolution or improvement of headaches after embolization.

Results Of 76 patients undergoing MMA embolization for a cSDH during the study period, $56(74 \%)$ had a discharge GCS of 15 . Of these 56 patients, 46 (82\%) responded to a follow-up phone call and were analyzed (mean (SD) age, 68 (11) years; 36 (78\%) men and 10 (22\%) women). Nine


Abstract P-041 Figure 1 (A) Axial computed tomogram (CT) of the head showing bilateral chronic subdural hematomas (CSDHs). (B-D) Cerebral angiography images showing bilateral middle meningeal artery embolization with Onyx (views: B, un-subtracted posteroanterior; C, right lateral, D, left lateral). (E) Axial head $\mathrm{CT}$ at 30-day follow-up shows significant improvement of bilateral CSDHs. Used with permission from barrow neurological institute, Phoenix, Arizona 
Abstract P-041 Table 2 Patient characteristic and outcome data of the severe chronic headache group

\begin{tabular}{|c|c|c|c|c|c|c|c|c|}
\hline \multirow[b]{2}{*}{ Case } & \multirow[b]{2}{*}{ Age } & \multirow[b]{2}{*}{ Sex } & \multirow{2}{*}{$\begin{array}{c}\text { Pre-embolization } \\
\text { medications for } \\
\text { headaches }\end{array}$} & \multirow{2}{*}{$\begin{array}{c}\text { Bilateral } \\
\text { embolization }\end{array}$} & \multirow{2}{*}{$\begin{array}{c}\text { Headaches after } \\
\text { embolization }\end{array}$} & \multicolumn{2}{|c|}{ HIT-6 score } & \multirow{2}{*}{$\begin{array}{c}\text { Phone } \\
\text { follow-up } \\
d^{*}\end{array}$} \\
\hline & & & & & & $\begin{array}{c}\text { Pre- } \\
\text { embolization }\end{array}$ & $\begin{array}{c}\text { Post- } \\
\text { embolization }\end{array}$ & \\
\hline 1 & 59 & Female & Acetaminophen & No & Resolved & 61 & 36 & 568 \\
\hline 2 & 45 & Female & Ibuprofen & No & $\begin{array}{l}\text { Worse, requires } \\
\text { more medication }\end{array}$ & 60 & 63 & 850 \\
\hline 3 & 77 & Male & None & Yes & Resolved & 57 & 36 & 621 \\
\hline 4 & 65 & Female & Triptan & No & $\begin{array}{l}\text { Improved, } \\
\text { requires less } \\
\text { medication }\end{array}$ & 67 & 44 & 527 \\
\hline 5 & 74 & Male & Ibuprofen & Yes & Resolved & 54 & 36 & 429 \\
\hline 6 & 74 & Male & None & Yes & Resolved & 60 & 36 & 405 \\
\hline 7 & 47 & Male & Aspirin & Yes & Resolved & 72 & 36 & 338 \\
\hline 8 & 72 & Female & Ibuprofen & Yes & Resolved & 70 & 36 & 304 \\
\hline 9 & 62 & Female & None & Yes & Resolved & 74 & 36 & 360 \\
\hline
\end{tabular}

Abstract P-041 Table 1 Demographics and characteristics of CSDH patients with a GCS score of 15 at discharge

\begin{tabular}{lc}
\hline Characteristics & $\begin{array}{c}\text { No. (\%) } \\
(\mathbf{n}=46)\end{array}$ \\
\hline Age, mean \pm SD, y & $68 \pm 11$ \\
Sex & \\
Female & $10(22)$ \\
Male & $36(78)$ \\
Chronic headache & $9(20)$ \\
Any headache before embolization & $25(54)$ \\
Any headache after embolization & $7(15)$ \\
New headache after embolization & $1(5)$ \\
(n=21 w/o previous headache) & \\
Complications & $0(0)$ \\
\hline
\end{tabular}

Abbreviations: cSDH, chronic subdural hematoma; GCS, Glasgow Coma Scale Data are reported as number (pereent) unless otherwise indicated.

(20\%) reported chronic headaches before embolization. With a mean follow-up of 489 (173) days, 8 of the 9 patients reported improvement of chronic headaches, with 7 having complete resolution. For these 9 patients, the mean HIT-6 score before was significantly higher than after embolization (64 [7.1] vs 40 [9.1], p<0.001).

Conclusion In patients with chronic headache undergoing MMA embolization for a cSDH, the majority reported improvement of headaches after the procedure. Future prospective studies are warranted to assess the utility of MMA embolization for chronic headaches.

Disclosures J. Catapano: None. K. Karahalios: None. V. Srinivasan: None. J. Baranoski: None. C. Rutledge: None. T. Cole: None. A. Ducruet: None. F. Albuquerque: None. A. Jadhav: None.

\section{P-042 INITIAL EXPERIENCE WITH TENECTEPLASE AS THE INTRAVENOUS THROMBOLYTIC OF CHOICE BEFORE MECHANICAL THROMBECTOMY FOR LARGE VESSEL OCCLUSION ACUTE ISCHEMIC STROKE}

\footnotetext{
${ }^{1,2} \mathrm{U}_{\text {Ugur, }}{ }^{1,2} \mathrm{~S}$ Platko, ${ }^{3} \mathrm{D}$ Peters, ${ }^{2} \mathrm{~F}$ Bensabeur, ${ }^{1,2} \mathrm{~J}$ Terry, ${ }^{1,2} \mathrm{~B}$ Ludwig, ${ }^{1,2} \mathrm{E}$ Cheng-Ching ${ }^{*}$. ${ }^{1}$ Neurology, Miami Valley Hospital, Dayton, $\mathrm{OH}_{;}{ }^{2}$ Neurology, Wright State University, Dayton, $\mathrm{OH} ;{ }^{3}$ Pharmacy, Miami Valley Hospital, Dayton, $\mathrm{OH}$
}

10.1136/neurintsurg-2021-SNIS.78
Introduction In mechanical thrombectomy (MT) candidates, tenecteplase (TNK) has shown improved reperfusion and outcomes. Therefore, in October of 2020, we transitioned to TNK as the primary thrombolytic for patients presenting with large vessel occlusion acute ischemic stroke (LVOAIS). We describe our initial experience.

Methods In this retrospective study, demographic, clinical, and imaging information from patients with LVOAIS treated with TNK was collected. Data was compared to a group treated with MT and intravenous alteplase (tPA).

Results Between October 2020 and March 2021, 14 patients received TNK for LVOAIS. Mean age was 71.4 years. Of the TNK patients, 5 presented directly to the comprehensive stroke center (CSC), and 9 were transferred from telestroke spoke sites within the system. Median initial NIHSS was 16. All patients had either an LVO on CTA, or high suspicion based on high NIHSS. Occlusion locations included the MCA in 9 (7 M1, 2 M3-4 with CTA obtained after TNK), ACA 1, PCA 1, ICA terminus 1 , and 2 with occlusion involving the internal carotid artery (ICA) from the origin to the terminus. Three patients (21\%) improved clinically prior to MT and did not undergo this intervention, and $2(14 \%)$ had a cerebral angiogram demonstrating recanalization without MT. One patient with occlusion from ICA origin to terminus underwent revascularization of the ICA origin with distal spontaneous recanalization. Eight patients underwent MT with 7 achieving TICI 2b-3. Symptomatic hemorrhage $(\mathrm{SICH})$ rate was $7.1 \%$. Length of stay (LOS) was 4.4 days, with median discharge NIHSS of 4. In comparison, of patients who received tPA prior to MT none recanalized prior to MT, median discharge NIHSS was 6 , rate of SICH was $5.1 \%$ and LOS was 8.54 days.

Discussion In our initial experience in a small cohort, the recanalization rate was high with TNK in patients with LVOAIS, with $36 \%$ of TNK patients not requiring MT either due to clinical improvement or recanalization pre-MT. In comparison, no patient who received tPA recanalized prior to MT. Discharge NIHSS and LOS was lower in patients receiving TNK.In light of evidence supporting TNK in LVOAIS, we were able to transition easily to adopt the use of TNK within our system. The practicality of a single bolus without subsequent infusion of TNK will likely improve the treatment process of LVOAIS patients by facilitating transfer from ER to the angio-suite as well as from spokes to hub. With 